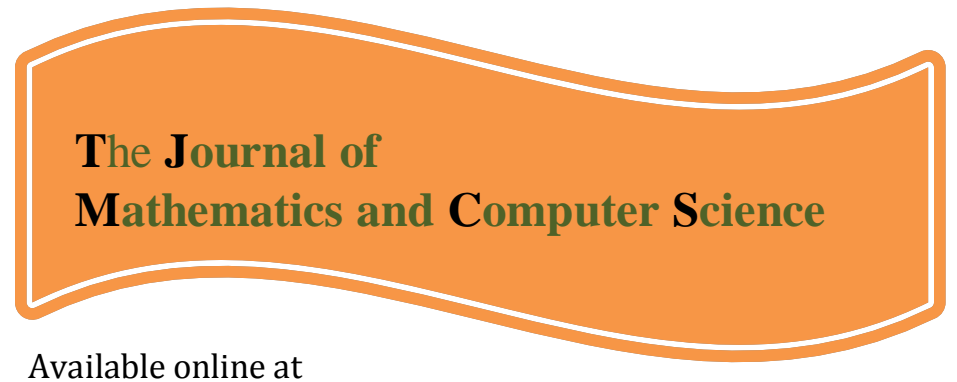

http://www.TJMCS.com

The Journal of Mathematics and Computer Science Vol .2 No.1 (2011) 171-183

\title{
The study of airline service quality in the Qeshm free zone by fuzzy logic Nahid Moones Toosi ${ }^{1}$, Reza Ahmadi kohanali ${ }^{2}$ \\ Islamic Azad University-Qeshm branch, na_moones@yahoo.com \\ Hormozgan University, r.ahmmadi@gmail.com
}

Received: September 2010, Revised: November 2010

Online Publication: January 2011

\section{Abstract}

This paper applies the fuzzy set theory for evaluating service quality of three airlines are active in Qeshm free zone in Iran via customer survey. Service quality is a composite of various attributes among them many intangible attributes are difficult to measure. So we invite fuzzy set theory to reflect the inherent subjectiveness and resolve the ambiguity of concepts that are associated with human beings'subjective judgments vaguely measured with linguistic terms. By applying AHP in obtaining criteria weight and TOPSIS in ranking, we find the relative ranking position of each airline and provide an adequate alternative to performance evaluation of airline services which usually involve subjective judgments of qualitative attributes.

Keywords: AHP, TOPSIS, Airline, Service quality

\section{Introduction}

The rapid growth in passenger traffic has been experienced in the airline market worldwide. Competition is ever increasing as airlines try to acquire and retain customers. This is due to the expansion of customers awareness of service quality. Price is initially used as the primary competitive weapon. However, airlines soon realize that competition on price alone represents a no-win situation in the long term. This is mainly due to the fact that airlines are relatively efficient in responding to competitors' price changes [29].This implies that in a highly competitive environment, airlines' competitive advantages lie in the service quality perceived by customers. And Defining and measuring quality service is of importance to providers of airline.

Airlines hope to consolidate the market share and enhance profitability. However, the marginal benefits of marketing strategies gradually reduce because most of the airlines act similarly. Recognizing this limitation of the marketing strategies, some of air carriers now tend to focus on the commitment of improving customer service quality.

The air carriers provide a range of services to customers including ticket reservation, purchase, airport ground service, on-board service and the service at the destination. Airline service also consists of the assistance associated with disruptions such as lost-baggage handling and service for delayed passengers. Service quality can be regarded as a composite of various attributes. It not only consists of tangible attributes, but also intangible/subjective

\footnotetext{
${ }^{1}$ MA student of Business Management - Marketing

${ }^{2}$ Assistant Professor of Production and Operation Management
} 
attributes such as safety, comfort, which are difficult to measure accurately. Different individual usually has wide range of perceptions toward quality service, depending on their preference structures and roles in process (service providers/receivers). To measure service quality, conventional measurement tools are devised on cardinal or ordinal scales. Most of the criticism about scale based on measurement is that scores do not necessarily represent user preference. This is because respondents have to internally convert preference to scores and the conversion may introduce distortion of the preference being captured.

Since service industry contains intangibility, perishability, inseparability and heterogeneity, it makes peoples more difficult to measure service quality. To explore the past related research document, most of the methods for evaluating airline service quality employs statistics method. 5-point of Likert Scales is the major way to evaluate service quality in the past. Nowadays, the fuzzy set theory has been applied to the field of management science, like decision making [26], [50], [57], however, it is scarcely used in the field of service quality. Lingual expressions, for example, satisfied, fair, dissatisfied, are regarded as the natural representation of the preference or judgement. These characteristics indicate the applicability of fuzzy set theory in capturing the decision makers' preference structure fuzzy set theory aids in measuring the ambiguity of concepts that are associated with human being's subjective judgment. Since the evaluation is resulted from the different evaluator's view of linguistic variables, its evaluation must therefore be conducted in an uncertain, fuzzy environment. During the process of evaluators are imprecise with too large an allowance for error. Therefore, this study includes Fuzzy Multiple Criteria DecisionMaking (MCDM) theory to strengthen the comprehensiveness and reasonableness of the decision making process. The rest of this study is structured as follows: The first part describes important aspects for the assessment of service quality of airline and presents the evaluation framework and methodology. Next part discusses the procedure and results of empirical study. The final results of the empirical study are presented and discussed in the final section.

\section{Evaluation framework and methods of airline service quality}

The evaluation procedure of this study consists of several steps as shown in Fig. 1. First, we identify the service quality aspects and attributes that customers consider the most important. After constructing the evaluation criteria hierarchy, we calculate the criteria weights by applying Analytic Hierarchy Process (AHP) method. The measurement of performance corresponding to each criterion is conducted under the setting of fuzzy set theory. Finally, we conduct Technique for Order Preference by Similarity to Ideal Solution (TOPSIS) to achieve the final ranking results. The

Detailed descriptions of each step are elaborated in each of the following sub-section

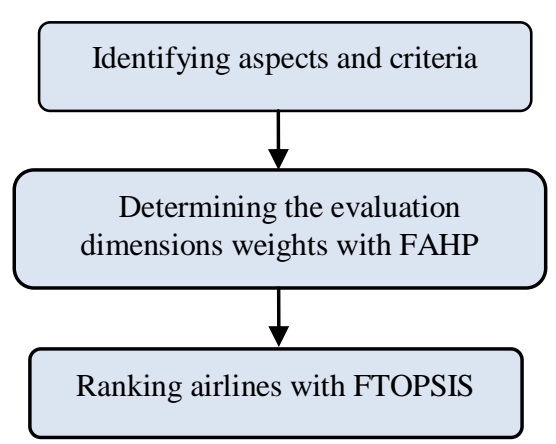

fig 1. Evaluation framework of airline service quality.

\subsection{Identification aspects and criteria}

The typical multiple criteria evaluation problem focuses on a set of feasible alternatives and considers more than one criterion to determine a priority ranking for alternative implementation. Keeney and Raiffa [30] suggest that five principles to be considered when criteria are being formulated: completeness, operational, decomposable, nonredundancy, and minimum size.

There are many empirical studies concerned about service quality. Parasuraman, Zeithaml, and Berry [41] proposed ten aspects of evaluation criteria in assessing service quality: tangibiles, reliability, responsiveness, communication, credibility, security, competence, courtesy, understanding/knowing customers and access. Many scholars measured the discrepancy in the perception of service quality between airline managers and passengers. Gourdin [21] have categorized airline service quality into three items: price, safety and timelines. Elliott and Roach [18] pointed out that timelines, the luggage transportation, the quality of F\&B, the comfort of seat, the check in process and inboard service are the six guidelines for evaluating airline service quality. In Ostrowski, O’Brien, and Gordon's [40] 
empirical study of service quality and customer royalty, they took timeliness, F\&B quality, comfort of seat as the factors of surveying service quality. Truitt and Haynes [49] uses the checking process, the convenience of transit, the process of luggage, the timeliness, the clearness of seat, the F\&B quality and the customer complaints handing as the standards for measuring service quality.

The study by Abrahams [2] provides empirical support for the theory of service quality competition in the airline industry. Empirical studies of demand for airline services show that service quality is central to the choice of airlines for both business and leisure travelers [8]. Zagat Research (2005) released a report in 2005 (www.zagat.com) on airline service quality. The study divided carriers into US domestic carriers and international carriers into the US (which included most of the major international airlines). The Zagat data was presented in four categories: comfort, service, food and web site. Three of the factors are clearly service delivery issues, but the web site score relates more to the ease of using the airline web site when purchasing. Zagat readers are left to examine each airline service category or add the four scores themselves for an overall score. Also in 2005, J.D. Power released the firm's first study on airline service quality since 2000 (J.D. Power, 2005). The study and its findings concentrated on only 11 of the US major airlines with no reported information on regional, emerging low costs or international carriers. A 1,000 point index score used in the study reported that JetBlue and Southwest came out on top.

Another study utilized the SERVQUAL scale adopted for an airline situation in 1994[47] and found the SERVQUAL factor of reliability (one example: excellent airlines will provide their services at the time they promise to do so) was the most important dimension among air passengers. Ekiz et al [19] developed an AIRQUAL scale to overcome the psychometrical application problems of the existing quality scales, in the guidance of Churchill [13] and Parasuraman et al [42], [43] The results of AIRQUAL revealed that the scale had five distinct dimensions (airline tangibles, terminal tangibles, personnel, empathy, and image) that successfully managed to measure the quality perceptions of airline customers in North Cyprus.

This study incorporates the eight-aspect representation of service quality proposed in earlier research. We extract them based on frequency of each of these aspects in previous studies and that should be able to make distinctions in the airlines also apply in Iran. Then with using the opinion of experts and specialists in the airline field, number of them was removed and Some changes took place. Then, they were designed in the form of conceptual model of study. The eight aspects include tangibility, reliability, responsiveness, assurance, Empathy, timelines, availability and convenience. Tangibility means the appearance of physical facilities, equipment, and neat appearance of employees [43] ; reliability stands for the passenger security and ability to perform the promised service dependably and accurately [43]; responsiveness aspect describes willingness to help customers and provide prompt service[43]; assurance aspect is knowledge and courtesy of employee and their ability to inspire trust and confidence[43]; assurance aspect stand for knowledge and courtesy of employees and their ability to inspire trust and confidence[43]; the empathy aspect is caring, individualized attention the employees provide customer and have a sympathetic manner with passenger[43]; timelines is on-time performance in accordance with time schedules [24]; availability aspect means prompt and easy availability of facilities and services and providing adequate information about process and service[25] and comfort aspect stand for comfortableness and convenience sensibility during using the facilities and services[25].

Taking the structure of the eight aspects as the skeleton and synthesize the other literatures as well as the practical consideration, we established these evaluation criteria include eight aspects and 44 service quality evaluation criteria, the details of which can be found in Table 1 .

\begin{tabular}{ll}
\hline Aspect & attribute \\
\hline \multirow{2}{*}{ Tangibility } & neat appearance of crew \\
& giving recent magazine and newspaper and new movie during the flight \\
& suitable food and beverage \\
& cabin comfort and attractiveness \\
& Availability of health services \\
& flight safety \\
& friendly and helping behavior of flight crew against passengers \\
Reliability & proper transfer and delivery of luggage and cargo \\
& availability of a sufficient number of crew \\
& avoiding flight cancelation \\
& keeping error-free records (tickets and other documents are no mistakes) \\
& availability of flights to each destination
\end{tabular}


Nahid Moones Toosi, Reza Ahmadi kohanali / TJMCS Vol .2 No.1 (2011) 171-183

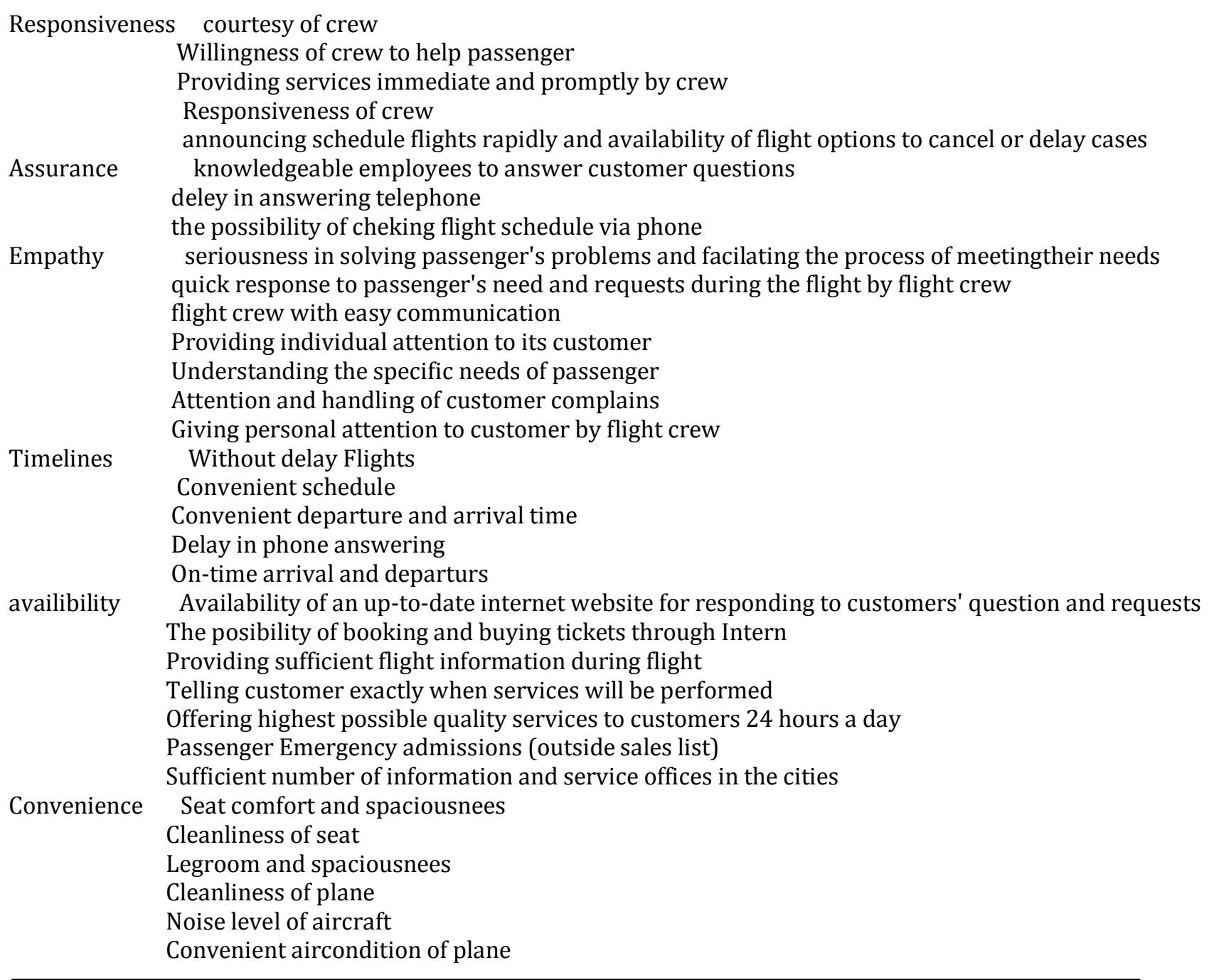

Table 1: The evaluation criteria for airline service quality

2.2. Fuzzy analytic hierarchy process (AHP)

Analytic hierarchy process (AHP) is a powerful method to solve complex decision problems. Any complex problem can be decomposed into several sub-problems using AHP in terms of hierarchical

levels where each level represents a set of criteria or attributes relative to each sub-problem. The AHP method is a multicriteria method of analysis based on an additive weighting process, in which several relevant attributes are represented through their relative importance. AHP has been extensively applied by academics and professionals, mainly in engineering applications involving financial decisions associated to non-financial attributes [14]. Through AHP, the importance of several attributes is obtained from a process of paired comparison, in which the relevance of the attributes or categories of drivers of intangible assets are matched two-on-two in a hierarchic structure. However, the pure AHP model has some shortcomings [58]. They pointed out that the AHP method is mainly used in nearly crisp-information decision applications; the AHP method creates and deals with a very unbalanced scale of judgment; the AHP method does not take into account the uncertainty associated with the mapping of human judgment to a number by natural language; the ranking of the AHP method is rather imprecise; and the subjective judgment by perception, evaluation, improvement and selection based on preference of decision-makers have great influence on the AHP results. To overcome these problems, several researchers integrate fuzzy theory with AHP to improve the uncertainty. Hence, Buckley [5] used the evolutionary algorithm to calculate the weights with the trapezoidal fuzzy numbers. The fuzzy AHP based on the fuzzy interval arithmetic with triangular fuzzy numbers and confidence index a with interval mean approach to determine the weights for evaluative elements.

2.3.building the evaluation hierarchy systems for evaluating the airlines service quality in the qeshm free. 
This research tries to evaluate service quality of three airlines in Qeshm free zone. After reviewing the related literature, we set criteria that building the evaluation hierarchy systems. Based on the evaluation criteria, this research lists the three airlines for improving the competitive advantage.

\subsection{Determining the evaluation dimensions weights}

With appling fuzzy AHP to fuzzify hierarchical analysis by allowing fuzzy numbers for the pairwise comparisons and find the fuzzy preference weights. In this section, we briefly review concepts for fuzzy hierarchical evaluation. Then, the following sections will introduce the computational process about fuzzy AHP in detail.

\subsubsection{Estabilishing Fuzzy number}

Fuzzy sets are sets whose elements have degrees of membership.Fuzzy sets have been introduced by Zadeh [60] as an extension of the classical notion of set. In classical set theory, the membership of elements in a set is assessed in binary terms according to a bivalent condition - an element either belongs or does not belong to the set [36], [56]. The mathematics concept borrowed from Hsieh et al [23]. A fuzzy number $\tilde{A}$ on $\mathrm{R}$ to be a TFN if its membership function $\mu(x)_{\tilde{A}}: \mathrm{R} \rightarrow[0,1]$ is equal to following Eq. (1):

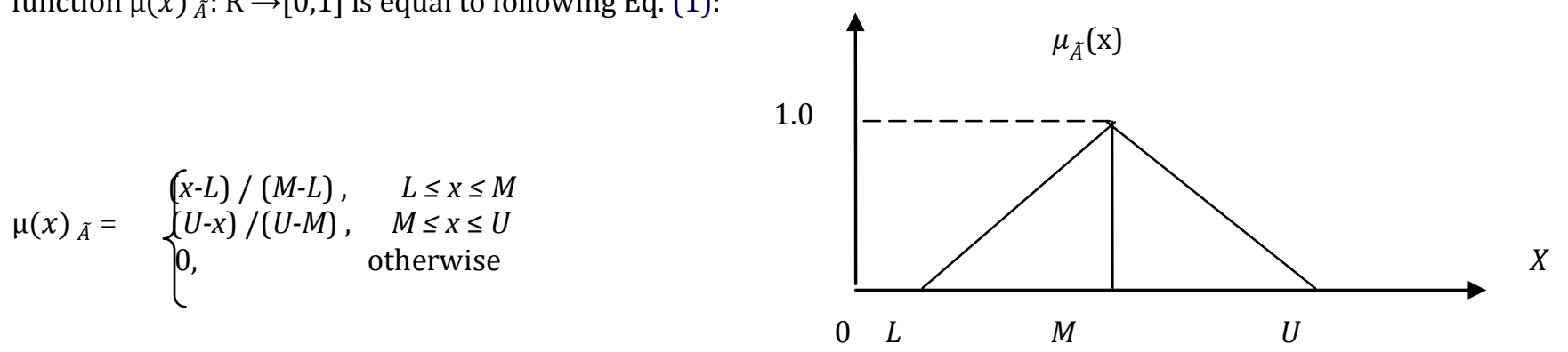

From Eq. (1), $L$ and $U$ mean the lower and upper bounds of the fuzzy number $\tilde{A}$, and $M$ is the modal value for $\tilde{A}$ (as Fig. 1). The TFN can be denoted by $\tilde{A}=(L, M, U)$. The operational laws of $\operatorname{TFN} \tilde{A}_{1}=\left(L_{1}, M_{1}, U_{1}\right)$ and $\tilde{A}_{2}=\left(L_{2}\right.$, $M_{2}, U_{2}$ ) are displayed as following Eqs. (2)-(7)

Comparing with the traditional investigative research, the importance degree for the serving attribute used 5-points of Likert Scale, applying TFN that the utilization of linguistic variables is rather widespread at the present time, and the linguistic values found in this study are primarily used to assess the linguistic ratings given by the evaluators. According to the nature of TFN and the extension principle put forward by Zadeh [60], the algebraic calculation of the triangular fuzzy number.

Addition of triangular fuzzy number

$$
\begin{aligned}
\left(L_{1}, M_{1}, U_{1}\right) & \oplus\left(L_{2}, M_{2}, U_{2}\right) \\
& =\left(L_{1}+L_{2}, M_{1}+M_{2}, U_{1}+U_{2}\right)
\end{aligned}
$$

Multiplication of a triangular fuzzy number $\otimes$

$$
\text { A. } \quad\left(L_{1}, M_{1}, U_{1}\right) \otimes\left(L_{2}, M_{2}, U_{2}\right) \text { For } L_{1}, L_{2}>0 ; M_{1}, M_{2}>0 ; U_{1}, U_{2}>0
$$

B. Any real number $\mathrm{k}$

$\mathrm{K} \otimes(\mathrm{L}, \mathrm{M}, \mathrm{U})=(\mathrm{K}, \mathrm{K}, \mathrm{K}) \otimes(\mathrm{L}, \mathrm{M}, \mathrm{U})$

$$
=(\mathrm{KL}, \mathrm{KM}, \mathrm{KU})
$$

Subtraction of a triangular fuzzy number $\Theta$

$$
\begin{aligned}
\left(L_{1}, M_{1}, U_{1}\right) & \ominus\left(L_{2}, M_{2}, U_{2}\right) \\
& =\left(L_{1}-L_{2}, M_{1}-M_{2}, U_{1}-U_{2}\right)
\end{aligned}
$$

Division of a fuzzy number $\emptyset$

$$
\begin{gathered}
\left(L_{1}, M_{1}, U_{1}\right) \emptyset\left(L_{2}, M_{2}, U_{2}\right)=\left(L_{1} / L_{2}, M_{1} / M_{2}, U_{1} / U_{2}\right) \\
\quad U_{1}, U_{2}>0
\end{gathered} \quad \text { For } L_{1}, L_{2}>0 ; M_{1}, M_{2}>0 ;
$$

Reciprocal of the fuzzy number

$$
\tilde{A}^{-1}=\left(L_{1}, M_{1}, U_{1}\right)^{-1}=\left(1 / U_{1}, 1 / M_{1}, 1 / L_{1}\right) \text { For } L_{1}, L_{2}>0 ; M_{1}, M_{2}>0 ; U_{1}, U_{2}>0
$$

\subsubsection{Determination linguistic variable}

Linguistic variables take on values defined in its term set: its set of linguistic terms. Linguistic terms are subjective categories for the linguistic variable. A linguistic variable is a variable whose values are words or sentences in a natural or artificial language. Here, we use this kind of expression to compare two airline evaluation dimension by five basic linguistic terms, as" Equal importance", " Weak importance (of one over the other)"," Strong importance" , 
"Demonstrated importance over the other"," Absolute importance", with respect to a fuzzy five level scale. In this paper, the computational technique is based on the following fuzzy numbers defined by [38] in Table 1. Here, each membership function (scale of fuzzy number) is defined by three parameters of the symmetric triangular fuzzy number, the left point, middle point, and right point of the range over which the function is defined.

Table2,Membership function of linguistic scale (example).

\begin{tabular}{lll}
\hline fuzzy number & linguistic & scale of fuzzy number \\
\hline 1 & Equal importance & $(1,1,1)$ \\
2 & Weak importance (of one over the other) & $(2,3,4)$ \\
3 & Strong importance & $(4,5,6)$ \\
4 & Demonstrated importance over the other & $(6,7,8)$ \\
5 & Absolute importance & $(8,9,10)$ \\
\hline
\end{tabular}

\section{Fuzzy AHP}

Then, we will briefly introduce that how to carry out the fuzzy AHP in the following sections.

Step1: Construct pairwise comparison matrices among all the elements/criteria in the dimensions of the hierarchy system. Assign linguistic terms to the pairwise comparisons by asking which is the more important of each two dimensions, as following matrix $\tilde{A}$

$$
\tilde{A}=\left[\begin{array}{cccc}
1 & \tilde{a}_{12} & \ldots & \tilde{a}_{1 n} \\
\tilde{a}_{21} & 1 & \ldots & \tilde{a}_{2 n} \\
\vdots & \vdots & \ddots & \vdots \\
\tilde{q}_{n 1} & \tilde{a}_{n 2} & \cdots & 1
\end{array}=\right] \begin{gathered}
1 \\
1 / \tilde{a}_{12} \\
\vdots \\
1 / \tilde{a}_{n 1}
\end{gathered}\left[\begin{array}{ccccc}
\tilde{a}_{12} & \ldots & \tilde{a}_{1 n} & \\
1 & & \ldots & \tilde{a}_{2 n} & \text { (8) } \\
\vdots & \ddots & & \vdots & \\
1 / \tilde{a}_{n 2} & \cdots & 1 &
\end{array}\right]
$$

Where

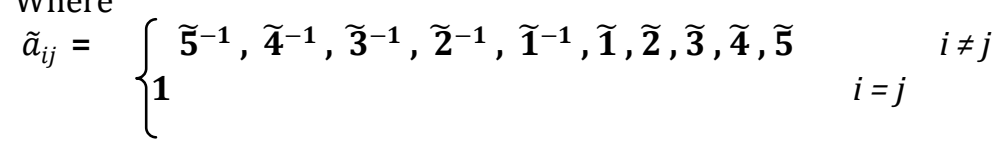

Step 2: To use geometric mean technique to define the fuzzy geometric mean and fuzzy weights of each criterion by Hsieh et al. [23]

$\tilde{r}_{i}=\left(\tilde{a}_{i 1} \otimes \tilde{a}_{i 2} \otimes \ldots \otimes \tilde{a}_{i j} \otimes \ldots \otimes \tilde{a}_{i n}\right)^{1 / n}$

$\widetilde{w}_{i}=\tilde{r}_{i} \otimes\left[\tilde{r}_{1} \oplus \tilde{r}_{2} \oplus \ldots \oplus \tilde{r}_{i} \oplus \ldots \oplus \tilde{r}_{n}\right]^{-1}$

where $\tilde{a}_{i j}$ is fuzzy comparison value of dimension i to criterion $\mathrm{j}$, thus, $\tilde{r}_{i}$ is a geometric mean of fuzzy comparison value of criterion i to each criterion, $\widetilde{w}_{i}$ is the fuzzy weight of the ith criterion, can be indicated by a TFN $\widetilde{w}_{i}=\left(L w_{i}, M\right.$ $w_{i}, U w_{i}$ ). The $L w_{i}, M w_{i}$ and $U w_{i}$ stand for the lower, middle, and upper values of the fuzzy weight of the ith dimension.

There are numerous studies that apply fuzzy AHP method to solve different managerial problems. Huang et al [27] adopt a fuzzy analytic hierarchy process method and utilize crisp judgment matrix to evaluate subjective expert judgments made by perception. Pan[41] applied fuzzy AHP model for selecting the suitable bridge construction method. Cakir and Canbolat [9] propose an inventory classification system based on the fuzzy analytic hierarchy process. Wang and Chen[52] applied fuzzy linguistic preference relations to construct a pairwise comparison matrix with additive reciprocal property and consistency. Sambasivan and Fei [45] evaluate the factors and sub-factors critical to the successful implementation of ISO 14001-based environmental management system and benefits. Sharma et al [46] used AHP method to optimize the selection of delivery network design followed by relevant choices for decision-making of Home plus distribution center. Costa and Vansnick [15] discussed the meaning of the priority vector derived from the principal eigenvalue method used in AHP. Firouzabadi et al [20] presented a decision support methodology for strategic selection decisions used a combination of analytic hierarchy process and zero-one goal programming to address the selection problem from the point of view of an individual stakeholder. Wang, Luo, and Hua [55] showed by examples that the priority vectors determined by the analytic hierarchy process 
method. Kuo et al [32] proposed group decision-making based on concepts of TOPIS technique for location section in fuzzy environment. Gumus [22] evaluates hazardous waste transportation firms containing the methods of fuzzy AHP and TOPSIS. Armillotta [3] described a computer-based tool for the selection of techniques used in the manufacture of prototypes and limited production runs of industrial products. The underlying decision model based on the AHP methodology, Tsaur et al [48] presented fuzzy AHP approach and TOPSIS to evaluation the service quality of 3 airlines in Tiwan. Hern Chang and Hsing Yeh [25] applied fuzzy multicriteria analysis (MA) approach for evaluating service quality of domestic passenger airlines by customer surveys in Tiwan .Chen, Tzeng and Ding [11] used fuzzy analytic hierarchy process to determine the weighting of subjective/perceptive judgments for each criterion and to derive fuzzy synthetic utility values of alternatives in a fuzzy multicriteria decision-making environment. Lin et al [35] proposed a framework that integrates the analytical hierarchy process and the technique for order preference by similarity to ideal solution to assist designers in identifying customer needs/requirements and design characteristics and help achieve an effective evaluation of the final design solution for achieving the aspired/desired levels.

\section{The fuzzy TOPSIS method}

In this study, we propose this method to evaluate the service quality of three airlines in Qeshm free zone. TOPSIS views a MADM problem with $m$ alternatives as a geometric system with $\mathrm{m}$ points in the n-dimensional space of criteria. The method is based on the concept that the chosen alternative should have the shortest distance from the positive-ideal solution (i.e., achieving the minimal gaps in each criterion) and the longest distance from the negativeideal solution (i.e., achieving the maximal levels in each criterion). TOPSIS defines an index called similarity to the positive-ideal solution and the remoteness from the negative-ideal solution. Then, the method chooses an alternative with the maximum similarity to the positive-ideal solution [28], [51]. It is often difficult for a decisionmaker to assign a precise performance rating to an alternative for the attributes under consideration. The merit of using a fuzzy approach is to assign the relative importance of attributes using fuzzy numbers instead of precise numbers for suiting the real world in fuzzy environment. This section extends the TOPSIS to the fuzzy environment [32], [59]. This method is particularly suitable for solving the group decision-making problem under fuzzy environment. We briefly review the rationale of fuzzy theory before the development of fuzzy TOPSIS. The mathematics concept borrowed from [6], [32] and [51].

Step 1: Determine the weighting of evaluation criteria. This research employs fuzzy AHP to find the fuzzy preference weights.

Step 2: Construct the fuzzy performance/decision matrix and choose the appropriate linguistic variables for the alternatives with respect to criteria

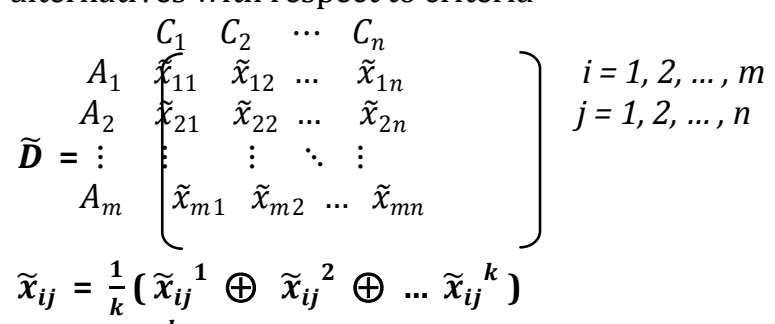

where $\widetilde{\boldsymbol{x}}_{\boldsymbol{i}}{ }^{\boldsymbol{k}}$ is the performance rating of alternative $\boldsymbol{A}_{\boldsymbol{i}}$ with respect to criterion $\boldsymbol{C}_{\boldsymbol{j}}$ evaluated by $\boldsymbol{k}$ th expert, and $\widetilde{\boldsymbol{x}}_{i j}{ }^{k}=\left(L_{i j}{ }^{k}, M_{i j}{ }^{k}, U_{i j}{ }^{k}\right)$

Step 3: Normalize the fuzzy-decision matrix. The normalized fuzzy-decision matrix denoted by $\widetilde{\boldsymbol{R}}$ is shown as following formula:

$\widetilde{\boldsymbol{R}}=\left[\tilde{r}_{i j}\right]_{m \times n} \quad i=1,2, \ldots, m ; j=1,2, \ldots, n$

Then, the normalization process can be performed by following formula:

$$
\left.\begin{array}{llll}
\tilde{\boldsymbol{r}}_{i j}=\left(\frac{L_{i j}}{U_{j}{ }^{+}}, \frac{M_{i j}}{U_{j}{ }^{+}}, \frac{U_{i j}}{U_{j}{ }^{+}}\right) & \text {where } & U_{j}{ }^{+}=\max U_{i j} \mid i=1,2,\{., m & \\
\tilde{\boldsymbol{r}}_{i j}=\left(\frac{L_{j}{ }^{-}}{U_{i j}}, \frac{L_{j}{ }^{-}}{M_{i j}}, \frac{U L_{j}{ }^{-}}{U_{i j}}\right) & \text { where } & L_{j}{ }^{-}=\min & L_{i j} \mid i=1,2,\{., m
\end{array}\right\}
$$

The normalized $\tilde{\boldsymbol{r}}_{i j}$ is still triangular fuzzy numbers. For trapezoidal fuzzy numbers, the normalization process can be conducted in the same way. The weighted fuzzy normalized decision matrix is shown as following matrix $\widetilde{\boldsymbol{V}}$ :

$$
\begin{aligned}
& \widetilde{\boldsymbol{V}}=\left[\tilde{V}_{i j}\right]_{m \times n} \quad i=1,2, \ldots, m ; j=1,2, \ldots, n \\
& \text { Where } \tilde{V}_{i j}=\tilde{r}_{i j} \otimes \widetilde{w}_{j}
\end{aligned}
$$


Step 4: Determine the fuzzy positive-ideal solution (FPIS) and fuzzy negative-ideal solution (FNIS). According to the weighted normalized fuzzy-decision matrix, we know that the elements $\tilde{V}_{i j}$ are normalized positive TFN and their ranges belong to the closed interval $[0,1]$. Then, we can define the FPIS $A^{+}$(aspiration levels) and FNIS $A^{-}$(the worst levels) as following formula:

$A^{+}=\left(\tilde{v}^{+}{ }_{1}, \tilde{v}^{+}{ }_{2}, \ldots, \tilde{v}_{j}^{+}, \ldots, \tilde{v}^{+}{ }_{n}\right)$

$A^{-}=\left(\tilde{v}_{1}^{-}, \tilde{v}^{-}{ }_{2}, \ldots, \tilde{v}_{j}^{-}, \ldots, \tilde{v}_{n}^{-}\right)$

Where $\quad \tilde{V}^{+}{ }_{j}=(1,1,1) \quad ; \quad \tilde{v}^{-}{ }_{j}=(0,0,0)$

Step 5: Calculate the distance of each alternative from FPIS and FNIS.

The distances $\left(\tilde{d}^{+}{ }_{i}\right.$ and $\tilde{d}^{-}{ }_{i}$ ) of each alternative from $A^{+}$and $A^{-}$can be currently calculated by the area compensation method

$\tilde{d}_{i}^{+}=\sum_{j=1}^{n}\left(\tilde{v}_{i j}, \tilde{v}^{+}{ }_{j}\right) \quad i=1,2, \ldots, m ; j=1,2, \ldots, n$

$\tilde{d}^{-}{ }_{i}=\sum_{j=1}^{n}\left(\tilde{v}_{i j}, \tilde{v}^{-}{ }_{j}\right) \quad i=1,2, \ldots, m ; j=1,2, \ldots, n$

Step 6: Obtain the closeness coefficients (relative gaps-degree) and improve alternatives for achieving aspiration levels in each criterion.

Opricovic and Tzeng [39] proposed a compromise solution by MCDM methods for comparative analysis of VIKOR and TOPSIS in EJOR; they pointed out the TOPSIS cannot be used for ranking purpose. Based on those concepts, the improved and chosen alternative should have the shortest distance from the positive-ideal solution (i.e., achieving the minimal gaps in each criterion) and the longest distance from the negative-ideal solution (i.e., achieving the maximal levels in each criterion).

Therefore, we propose the $C C i$ is defined to determine the fuzzy gaps-degree based on fuzzy closeness coefficients for improving alternatives; once the $\tilde{d}^{+}{ }_{i}$ and $\tilde{d}^{-}{ }_{i}$ of each alternative have been calculated. Calculate similarities to ideal solution. This step solves the similarities to an ideal solution by formula:

$$
\boldsymbol{C C} \boldsymbol{i}=\frac{\widetilde{\boldsymbol{d}}^{-}{ }_{\boldsymbol{i}}}{\widetilde{\boldsymbol{d}}^{-}{ }_{\boldsymbol{i}}+\widetilde{\boldsymbol{d}}^{+}{ }_{\boldsymbol{i}}} \quad i=1,2, \ldots, m
$$

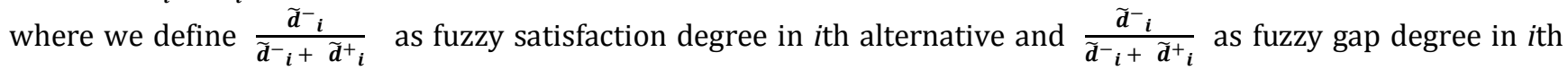
alternative. We can know which and how fuzzy gaps should be improved for achieving aspiration levels and getting the best win-win strategy from among a fuzzy set of feasible alternatives.

\section{Empirical study of airline service quality}

The questionnaire of service quality evaluation mainly was composed of two parts: questions for evaluating the relative importance of criteria and airline's performance corresponding to each criterion. AHP method was used in obtaining the relative weight of criteria. As for the performance corresponding to criteria of every airline, we used linguistic expression to measure the expressed

performance. In order to establish the membership function associated with each linguistic expression term, we asked respondents to specify the range from 1 to 10 corresponding to linguistic term. These score were later pooled to calibrate the membership functions. We picked three air carriers that active in Qeshm free zone in Iran as the objects of this empirical study. they were Aseman, Iranair, Farsair Qeshm.

Step 1: The weights of evaluation dimensions. We adopt fuzzy AHP method to evaluate the weights of different dimensions for the performance of airlines. Following the construction of fuzzy AHP model, it is extremely important that experts fill the judgment matrix. The following section demonstrates the computational procedure of the weights of dimensions.

(1) According to the committee with 19 representatives about the relative important of dimension, then the pairwise comparison matrices of dimensions will be obtained. We apply the fuzzy numbers defined in Table2. We transfer the linguistic scales to the corresponding fuzzy numbers.

(2) Computing the elements of synthetic pairwise comparison matrix (A) by using the geometric mean method by following formula:[5]

$\tilde{a}_{i j}=\left(\tilde{a}^{1}{ }_{i j} \otimes \ldots \otimes \tilde{a}^{19}{ }_{i j}\right)^{1 / 19}$

(3) calculating the fuzzy weights of dimensions

$r_{\text {tan }}=(3.98,4.35,4.89), \quad r_{\text {rel }}=(11.27,12.32,13.39)$,

$r_{\text {assu }}=(7.60,8.29,9.41)$,

$r_{\text {emp }}=(6.51,7.06,8.03)$,

$r_{\text {res }}=(8.58,9.38,10.35)$,

$r_{\text {avai }}=(7.82,8.59,9.66)$,

$r_{\text {con }}=(10.45,11.30,12.51)$

$w$ tan $=(0.052,0.061,0.073)$

$w$ rel $=(0.147,0.173,0.201)$,

$(0.099,0.116,0.141), \quad w$ emp $=(0.085,0.99,0.012)$,

avai $=(0.102,0.112,0.145)$,

$w$ con $=(0.136,0.158,0.188)$

$$
r_{\text {tim }}=(8.30,9.43,10.27)
$$

$w$ res $=(0.111 .0 .131 .0 .158)$,

$w$ tim $=(0.108,0.132,0.161)$,

w assu $=$

W 
(4). To apply the COA method to compute the BNP value of the fuzzy weights of each dimension.the calculation process is as follows:

$\mathrm{BNP} w_{i}=\left[\left(U w_{i}-L w_{i}\right)+\left(M w_{i}-L w_{i}\right) / 3+L w_{i}\right.$

Then, the weights for the remaining dimensions can be found as shown in Table 3. Table 3 shows the relative weight of eight dimensions of the evaluation of airlines service quality.

\begin{tabular}{lcccc}
\hline dimention & weights & BNP & rank & \\
\hline tangibility & $(0.052,0.061,0.073)$ & 0.063 & 8 & \\
reliability & $(0.147,0.173,0.201)$ & 0.95 & 1 & \\
responsiveness & $(0.111 .0 .131 .0 .158)$ & 0.130 & 3 & \\
assurance & $(0.099,0.116,0.14$ & 0.112 & 6 & \\
empathy & $(0.085,0.99,0.012)$ & 0.097 & 7 & \\
timelines & $(0.108,0.132,0.161)$ & 0.130 & 4 & \\
availability & $(0.136,0.158,0.188)$ & 0.116 & & 5 \\
convenience & $(0.102,0.112,0.145)$ & 0.156 & & 2 \\
\hline
\end{tabular}

table3, Weights of dimensions.

\begin{tabular}{lc}
\hline Linguistic variable & Corresponding triangular fuzzy number \\
\hline Very poor (VP) & $(0,1,3)$ \\
Poor (P) & $(1,3,5)$ \\
Fair (F) & $(3,5,7)$ \\
Good (G) & $(5,7,9)$ \\
Very good (VG) & $(7,9,10)$ \\
\hline
\end{tabular}

table4, Linguistic scales for the rating of each airline.

Fig. 4 shows the relative weights of the eight aspects of service quality, which are obtained by applying AHP. The weights for each of the aspect are: reliability (0.95), convenient $(0.156)$,timelines $(0.130)$ assurance $(0.130)$, availability(0.116), empathy (0.097)and tangibility (0.063). The weights describe in general that customer more concern the reliability aspect than the other aspects. Ranked by the weights, the top six evaluation criteria are: flight safety (0.064), knowledgeable employees to answer customer questions (0.050), without delay Flights (0.045), Convenient aircondition of plane (0.043), announcing schedule flights rapidly and availability of flight options to cancel or delay cases

Step 2: Construct the fuzzy-decision matrix and choose the appropriate linguistic variables for the alternatives with respect to criteria.

This paper focus on evaluating the service quality of three airlines in Qeshm free zone; so, we assume that questionnaire has collected completely and will start with building dataset that are collected. The evaluators have their own range for the linguistic variables employed in this study according to their subjective judgments [14].

For each evaluator with the same importance, this study employs the method of average value to integrate the fuzzy/vague judgment values of different evaluators regarding the same evaluation dimensions. The evaluators then adopted linguistic terms (see Table4), including "very poor", "poor", "fair", "good" and "very good " to express their opinions about the rating of every airlines regarding each capability criteria, based on viewpoint of passenger have used the service of every three air carriers in Qeshm listed in Table 5. Using Eq. (10), we can normalize the fuzzydecision matrix as Table6.

Step 4: Establish the weighted normalized fuzzy-decision matrix. The forth step in the analysis is to find the weighted fuzzy-decision matrix; the resulting fuzzy-weighted decision matrix is shown

as Table7.

Step 5: Determine the fuzzy positive and fuzzy negative-ideal reference points. Then, we can define the fuzzy positive-ideal solution (FPIS) and the fuzzy negative-ideal solution (FNIS) as: $A^{+}=(1,1,1)$ and $A^{-}=(0,0,0)$.This is the fifth step of the fuzzy TOPSIS analysis. In order to calculate the closeness coefficients of each of the alternatives $d_{1}{ }^{+}$and $d_{1}{ }^{-}$calculation is used as an example as follows: $d_{1}{ }^{+}=7.311 \quad d_{1}{ }^{-}=0.757$

\begin{tabular}{llrr}
\hline & Aseman & Iranair & \multicolumn{2}{c}{ Farsair gheshm } \\
\hline tangibility & $(3.48,5.37,7.34)$ & $(4.15,6.15,8.05)$ & $(2.88,4.81,6.81)$
\end{tabular}


Nahid Moones Toosi, Reza Ahmadi kohanali / TJMCS Vol .2 No.1 (2011) 171-183

$\begin{array}{lc}\text { reliability } & (3.59,5.46,7.47) \\ \text { responsiveness } & (3.83,5.67,7.65) \\ \text { assurance } & (3.14,5.08,6.85) \\ \text { empathy } & (3.24,5.12,7.04) \\ \text { timelines } & (3.28,4.71,7.09) \\ \text { availability } & (2.98,4.85,6.84) \\ \text { convenience } & (3.17,5.01,7)\end{array}$
$(4.44,6.44,8.24)$
$(4.24,6.22,8.08)$
$(4.1,6.08,7.89)$
$(3.94,5.89,7.73)$
$(3.93,5.88,7.71)$
$(3.76,5.69,7.54)$
$(3.74,5.66,7.64)$
$(2.96,4.84,6.83)$
$(3.25,5.16,7.15)$
$(2.75,4.57,6.56)$
$(3.12,5.03,7)$
$(2.38,4.22,6.22)$
$(2.1,3.87,5.85)$
$(2.37,4.14,6.11)$

Table 5,Subjective cognition results of evaluators towards the five levels of linguistic variables

\begin{tabular}{lccc}
\hline & Aseman & Iranair & Farsair gheshm \\
\hline tangibility & $(0.43,0.67,0.91)$ & $(0.52,0.76,1)$ & $(0.36,0.6,0.85)$ \\
reliability & $(0.44,0.66,0.91)$ & $(0.54,0.78,1)$ & $(0.36,0.59,0.83)$ \\
responsiveness & $(0.47,0.7,0.95)$ & $(0.52,0.77,1)$ & $(0.4,0.64,0.88)$ \\
assurance & $(0.4,0.64,0.87)$ & $(0.52,0.77,1)$ & $(0.35,0.58,0.83)$ \\
empathy & $(0.42,0.66,0.91)$ & $(0.51,0.76,1)$ & $(0.45,0.65,0.91)$ \\
timelines & $(0.43,0.61,0.92)$ & $(0.51,0.76,1)$ & $(0.38,0.55,0.81)$ \\
availability & $(0.4,0.64,0.91)$ & $(0.5,0.75,1)$ & $(0.28,0.51,0.78)$ \\
convenience & $(0.41,0.66,0.92)$ & $(0.49,0.74,1)$ & $(0.31,0.68,0.8)$ \\
\hline
\end{tabular}

Table 6,Weighted normalized fuzzy-decision matrix.

Once the distances from FPIS and FNIS are determined, the closeness coefficient can be obtained with Eq. (16).

\begin{tabular}{lcccc}
\hline & $d_{i}{ }^{-}$ & $d_{i}{ }^{+}$ & Similarity to ideal solution $\left(c c_{i}\right)$ & final rank \\
\hline Aseman & 0.757 & 7.311 & 0.094 & $\mathbf{2}$ \\
Iranair & 0.831 & 7.230 & 0.104 & $\mathbf{1}$ \\
Farsair gheshm & 0.666 & 7.394 & 0.083 & $\mathbf{3}$ \\
\hline
\end{tabular}

Table 7,Closeness coefficients to aspired level among different companies.

\section{Conclusions and implications}

The concept of quality service goes beyond the technical aspects of providing the service-it includes customers' perception of what the services should be and how the services is to be conveyed. In investigating both concerns, we establish the procedures for identifying the most important attributes of service quality for customers and capture customers'assessment of three airlines based on these attributes. The evaluation procedures consists of the following steps: (1) identify the evaluation criteria for airline service quality; (2) assess the average importance of each criterion by Analytic Hierarchical Process over all the respondents. (3) represent the performance assessment of air carriers for each criterion by fuzzy numbers, which explicitly attempts to accurately capture the real preference of assessors. Individual assessment then is aggregated as an overall assessment for each airline under each criterion. (4) Use TOPSIS as the main device in ranking the service quality of the three air carriers. The significant findings of this study cover several perspectives. Customers are mainly concerned about the reliability aspect of the service and less concerned about the tangibility aspect. The finding suggests that airlines should maintain their physical features about a certain level and keep renovation necessary. Among the 44service criteria, the most important attributes are comfort flight safety, knowledgeable employees to answer customer questions, without delay Flights, Convenient aircondition of plane and announcing schedule flights rapidly and availability of flight options to cancel or delay cases. Airline manager also should be more committed to management improvement and be alert the implication of poor management to service quality.

The final ranking results show that Iranair is the best of the three airlines in terms of service quality, followed by Aseman and Farsair Qeshm.

This suggests that airlines pay more attention to reliability aspect and its criteria such as flights safety, proper transfer and delivery of luggage and cargo and avoiding flight cancelation. Also about convenience aspect .because 
one of the reason of choosing air journey is comfortablity. But on old Iranian airplanes and not up-to-date airlines it is not accuring.

In traditional investigative research, the importance degree for the serving attribute used the 5-points of Likert Scale. In this paper, we used the AHP rule and the concept of hierarchical structure to make the pairwise comparison among elements. In cases where there are many attributes, the investigation time is increased and the interviewee may feel impatient. Interactive design using the computer aid system can be used, and the above disadvantage may be improved. On other hand, we use the fuzzy approach on vague objects such as the satisfaction of airline service quality. In this study, using the membership function to measure the linguistic variables to achieve the better result, which can fairly and exactly reflects the different service quality of each airline. Therefore, the fuzzy logic, thinking and results of the fuzzy approach are better than the traditional statistic approach.

This study possess a few limitations. Firstly, our survey respondents were chosen from experts and professionals due to sample size limitation and response quality considerations. Second, too number of questions for responding in pairwise questionnaire.

\section{References}

1. Abo-Sinna, M.-A., Amer, A.-H., \& Ibrahim, A.-S. (2008). Extensions of TOPSIS for large scale multi-objective non-linear programming problems with block angular structure. Applied Mathematical Modelling, 32(3), 292-302.

2. Abrahams, M., 1983. A service quality model of air travel demand: An empirical study. Transportation Research Part A 17A (5), 385-393.

3. Armillotta, A. (2008). Selection of layered manufacturing techniques by an adaptive AHP decision model. Robotics and Computer-Integrated Manufacturing, 24(3), 450-461.

4. Benitez, J.-M., Martin, J.-C., \& Roman, C. (2007). Using fuzzy number for measuring quality of service in the hotel industry. Tourism Management, 28(2), 544-555.

5. Buckley, J.-J. (1985). Fuzzy hierarchical analysis. Fuzzy Sets and Systems, 17(1), 233-247.

6. Büyükzkan, G., Feyziog lu, O., \& Nebol, E. (2007). Selection of the strategic alliance partner in logistics value chain. International Journal of Production Economics, 113(1), 148-158.

7. Bureau of Transport and Communications Economics, 1992. Quality of service in Australian passenger aviation. Australian Government Publishing Service, Canberra.

8. Bureau of Transport and Communications Economics, 1994. International aviation trends and issues. Australian Government Publishing Service, Canberra. Butler, G.F., Keller, M.R., 1992. The cost-constrained

9. Cakir, O., \& Canbolat, M.-S. (2008). A web-based decision support system for multicriteria inventory classification using fuzzy AHP methodology. Expert Systems with Applications, 35(3), 1367-137.

10. Chen, C.-T., Lin, C.-T., \& Huang, S.-F. (2006). A fuzzy approach for supplier evaluation and selection in supply chain management. International Journal of Production Economics, 102(2), 289-301.

11. Chen, M.-F., Tzeng, G.-H., \& Ding, C.-G. (2008). Combining fuzzy AHP with MDS in identifying the preference similarity of alternatives. Applied Soft Computing, 8(1), 110-117.

12. Chen, T.-Y., \& Tsao, C.-Y. (2008). The interval-valued fuzzy TOPSIS method and experimental analysis. Fuzzy Sets and Systems, 159(11), 1410-1428.

13. Churchill, G. (1979), "A paradigm for developing better measures of marketing constructs", Journal of Marketing Research, Vol. 16, pp. 64-73.

14. Chi Sun, C., 2010, A performance evaluation model by integrating fuzzy AHP and fuzzy TOPSIS methods, Expert System with Applications, No 5, pp. 421-521.

15. Costa, C.-A.-B., \& Vansnick, J.-C. (2008). A critical analysis of the eigenvalue method used to derive priorities in AHP. European Journal of Operational Research, 187(3), 1422-1428.

16. Dagdeviren, M., \& Yuksel, I. (2008). Developing a fuzzy analytic hierarchy process (AHP) model for behavior-based safety management. Information Sciences, 178(6), 1717-1733.

17. Dubois, D., \& Prade, H. (1978). Operations on fuzzy number International Journal of System Science, 9(6), 613-626.

18. Elliott, K., \& Roach, D. W. (1993). Service quality in the airline industry: are carriers getting an unbiased evaluation from consumers? Journal of Professional Service Marketing, 9(2), 71-82.

19. Ekiz, H.E., Hussain, K. and Bavik, A. (2006), "Perceptions of service quality in North Cyprus national airline", Tourism and Hospitality Industry 2006 - New Trends in Tourism and Hospitality Management, Proceedings of 18th Biennial International Conference, Croatia: Faculty of Tourism and Hospitality Management, Opatija, May 3-5, Vol. 03-05, pp. 778-90. 
20. Firouzabadi, S.-M.-A.-K., Henson, B., \& Barnes, C. (2008). A multiple stakeholders' approach to strategic selection decisions. Computers and Industrial Engineering, 54(4), 851-865.

21. Gourdin, K. (1988). Bringing quality back to commercial travel. Transportation Journal, 27(3), 23-29.

22. Gumus, A.-T(2009).Evaluation of hazardous waste transportation firms buy using a two step fuzzy-AHP and TOPSIS methodology, Expert System with Application, 36(2), 4067-4074.

23. Hsieh, T.-Y., Lu, S.-T., \& Tzeng, G.-H. (2004). Fuzzy MCDM approach for planning and design tenders selection in public office buildings. International Journal of Project Management, 22(7), 573-584.

24. Hsieh, L., Huang Lin, L. \&.Yin Lin, Y., (2008), A service quality measurement architecture for hot spring hotels in Taiwan, Tourism Management, No.29, pp.429-438.

25. Hern Chang, Y. \& Hsing Yeh, C., 2002, A servey analysis of service quality for domestic airlines, European Journal of Operational Research, No.139, pp. 166-177.

26. Hutchinson, M. O. (1998). The use of fuzzy logic in business decisionmaking.Derivatives Quaterly, 4(4), 5367.

27. Huang, C.-C., Chu, P.-Y., \& Chiang, Y.-H. (2008). A fuzzy AHP application in government-sponsored R\&D project selection. Omega, 36(6), 1038-1052.

28. Hwang, C.-L., \& Yoon, K. (1981). Multiple attribute decision making: methods and applications. In Lecture notes in economics and mathematical systems. Now York: Springer. Hutchinson, M. O. (1998). The use of fuzzy logic in business decisionmaking. Derivatives Quaterly, 4(4), 53-67.

29. Jones, T.O., Sasser, W.E., 1995. Why satisfied customers defect. Harvard Business Review 73 (6), 88-99.

30. Keeney, R., \& Raiffa, H. (1976). Decision with multiple objective: Preference and value tradeoffs. New York: Wiley.

31. Kahraman, c, Sezi, A., Nüfer, Y., \& Gülbay, M. (2007). Fuzzy multi-criteria evaluation of industrial robotic systems. Computers and Industrial Engineering, 52(4), 414-433.

32. Kuo, M.-S., Tzeng, G.-H., \& Huang, W.-C. (2007). Group decision making based on concepts of ideal and antiideal points in fuzzy environment. Mathematical and Computer modeling, 45(3/4), 324-339. Keeney, R., \& Raiffa, H. (1976). Decision with multiple objective:Preference and value tradeoffs. New York: Wiley.

33. Li, D.-F. (2007). Compromise ratio method for fuzzy multi-attribute group decision making. Applied Soft Computing, 7(3), 807-817.

34. Lin, H.-T., \& Chang, W.-L. (2008). Order selection and pricing methods using flexible quantity and fuzzy approach for buyer evaluation. European Journal of Operational Research, 187(2), 415-428.

35. Lin, M.-C., Wang, C.-C., Chen, M.-S., \& Chang, C.-A. (2008). Using AHP and TOPSIS approaches in customerdriven product design process. Computers in Industry, 59(1), 17-31.

36. Liou, J.-J.-H., Yen, L., \& Tzeng, G.-H. (2007). Building an effective safety management system for airlines. Journal of Air Transport Management, 14(1), 20-26.

37. Moutinho, L., \& Curry, B. (1994). Modelling site location decisions in tourism. Journal of Travel \& Tourism Marketing, 3(2), 35-56.

38. Onut, S., Soner Kara, S., Isik, E., 2009, Long term supplier selection using a combined fuzzy MCDM approach: A case study for a telecommunication company, Expert System with Applications, No.36, pp. 63887-63895.

39. Opricovic, S., \& Tzeng, G.-H. (2004). Compromise solution by MCDM methods: A comparative analysis of VIKOR and TOPSIS. European Journal of Operational Research, 156(2), 445-455.

40. Ostrowski, P. L., O’Brien, T. V., \& Gordon, G. L. (1993). Servicequality and customer loyalty in the commercial airline industry. Journal of Travel Research, 32(2), 16-24.

41. Pan, N.-F. (2008). Fuzzy AHP approach for selecting the suitable bridge construction method. Automation in Construction, 17(8), 958-965.0nut, S , Kara, S.\& Elif L.I, (2009), Long term supplier selection using a combined fuzzy MCDM approach: A case study for a telecommunication company ,Expert Systems with Applications ,(36), 3887-3895

42. Parasuraman, A., Zeithaml, V.A. and Berry, L.L. (1985), "A conceptual model of service quality and its implications for future research", Journal of Marketing, Vol. 49, pp. 41-50.

43. Parasuraman, A., Zeithaml, V.A. and Berry, L.L. (1988), "SERVQUAL: a multiple-item scale for measuring consumer perceptions of service quality", Journal of Retailing, Vol. 64 No. 1,pp. 12-40.

44. Ryan, C. (1991). Recreational tourismFa social science perspective. London: Routledge.

45. Sambasivan, M., \& Fei, N.-Y. (2008). Evaluation of critical success factors of implementation of ISO 14001 using analytic hierarchy process (AHP): A case study from Malaysia. Journal of Cleaner Production, 16(13), 1424-1433. 
46. Sharma, M.-J., Moon, I., \& Bae, H. (2008). Analytic hierarchy process to assess and optimize distribution network. Applied Mathematics and Computation, 202(1),256-265.

47. Sultan, F. and Simpson, M. (2000), "International service variants: airline passenger expectations and perceptions of service quality", Journal of Services Marketing, Vol. 14 No. 3, pp. 188-216.

48. Tsuar,T-H, Chang. T-Y\& Yen, C-H, The evaluation of airline service quality by fuzzy MCDM, (2002), Tourism Management( 23 )107-115

49. Truitt, L. J., \& Haynes, R. (1994). Evaluating service quality and productivity in the regional airline industry. Transportation Journal, 33(2), 21-32.

50. Viswanathan, M. (1999). Understanding how product attributes influence product categorization: development and validation offuzzy set-based measures of gradedness in product categories. Journal of Marketing Research, 36(1), 75-95.

51. Wang, T.-C., \& Chang, T.-H. (2007). Application of TOPSIS in evaluating initial training aircraft under a fuzzy environment. Expert Systems with Applications, 33(4), 870-880.

52. Wang, T.-C., \& Chen, Y.-H. (2008). Applying fuzzy linguistic preference relations to the improvement of consistency of fuzzy AHP. Information Sciences, 178(19), 3755-3765.

53. Wang, Y.-M., \& Elhag, T.-M.-S. (2006). Fuzzy TOPSIS method based on alpha level sets with an application to bridge risk assessment. Expert Systems with Applications, 31(2), 309-319.

54. Wang, Y.-J., \& Lee, H.-S. (2007). Generalizing TOPSIS for fuzzy multiple-criteria group decision-making. Computers and Mathematics with Applications, 53(11), 1762-1772.

55. Wang, Y.-M., Luo, Y., \& Hua, Z. (2008). On the extent analysis method for fuzzy AHP and its applications. European Journal of Operational Research, 186(2), 735-747.

56. Wu, W.-W., \& Lee, Y.-T. (2007). Developing global managers' competencies using the fuzzy DEMATEL method. Expert Systems with Applications, 32(2), 499-507.

57. Xia, X., Wang, Z., \& Gao, Y. (2000). Estimation of non-statistical uncertainty using fuzzy-set theory. Measurement Science \&Technology, 11(4), 430-435.

58. Yang, C.-C., \& Chen, B.-S. (2004). Key quality performance evaluation using fuzzy AHP. Journal of the Chinese Institute of Industrial Engineers, 21(6), 543-550.

59. Yang, T., \& Hung, C.-C. (2007). Multiple-attribute decision making methods for plant layout design problem. Robotics and Computer-Integrated Manufacturing, 23(1), 126-137.

60. Zadeh, L.- A. (1965). Fuzzy sets. Information and Control, 8(2), 338-353. 